\title{
FORMAS DE ATUAÇÃO DO FISIOTERAPEUTA EM PRIMEIROS SOCORROS NAS MODALIDADES DESPORTIVAS: UMA REVISÃO DA LITERATURA BRASILEIRA
}

\author{
FORMAS DE DESEMPEÑO DEL FISIOTERAPEUTA EN PRIMEROS AUXILIOS EN \\ MODALIDADES DEPORTIVAS: UNA REVISIÓN DE LITERATURA BRASILEÑA
}

\author{
PHYSICAL THERAPISTS PRACTICE FORMS IN SPORTS FIRST AID: A BRAZILIAN \\ LITERATURE REVIEW
}

\author{
Suelena PONTE DA SILVA ${ }^{1}$ \\ Stela LOPES SOARES ${ }^{2}$ \\ Paulo Adriano SCHWINGEL ${ }^{3}$
}

RESUMO: Os primeiros socorros são os atendimentos prestados às vítimas de qualquer acidente ou mal súbito antes da chegada do médico, da ambulância ou de qualquer profissional qualificado da área de saúde. O presente estudo tem como objetivo identificar a forma de atuação do fisioterapeuta em primeiros socorros no esporte. Trata-se de uma revisão de literatura, em que foram utilizados 2 livros e 8 artigos científicos obtidos nas bases de dados LILACS, MEDLINE e SciELO, no período compreendido entre janeiro e março de 2018. Os resultados demonstraram que o fisioterapeuta atua nos primeiros socorros desportivos por meio da realização do método PRICE. Porém, torna-se necessário a realização de novos estudos que enfatizem esse tema, para que assim possamos contar com maior aporte teórico. A maioria dos estudos analisados relatou o papel da fisioterapia mais voltado para a realização de medidas preventivas e para a reabilitação propriamente dita.

PALAVRAS-CHAVE: Esporte. Fisioterapia. Primeiros Socorros.

RESUMEN: Los primeros auxilios son los cuidados proporcionados a las víctimas de cualquier accidente o lesión repentina antes de la llegada del médico, la ambulancia o cualquier profesional sanitario calificado. El presente estudio tiene como objetivo identificar la forma de actuación del fisioterapeuta en primeros auxilios en el deporte. Se trata de una revisión bibliográfica, en la que se utilizaron 2 libros y 8 artículos científicos obtenidos en las bases de datos LILACS, MEDLINE y SciELO, en el período comprendido entre de enero a marzo 2018. Los resultados demostraron que el fisioterapeuta actuará en los primeros auxilios deportivos por medio de la realización del método PRICE. Sin embargo, se hace necesario la realización de nuevos estudios que enfaticen ese tema, para que así podamos contar con mayor aporte teórico. La mayoría de los estudios analizados relató el papel de la fisioterapia más

${ }^{1}$ Centro Universitário INTA (UNINTA), Sobral - CE - Brasil. Especialista em Saúde Pública e Saúde da Família pelo Centro Universitário INTA (UNINTA). ORCID: <http://orcid.org/0000-0002-3761-0035>. E-mail: suelena1@ hotmail.com

${ }^{2}$ Faculdade Novo Tempo (FNT), Tianguá - CE - Brasil. Coordenadora do Curso de Fisioterapia. ORCID: <http://orcid.org/0000-0002-5792-4429>.E-mail: stela.soares@uninta.edu.br

${ }^{3}$ Universidade de Pernambuco (UPE), Petrolina - PE - Brasil. Professor Adjunto e Coordenador do Programa de Pós-Graduação em Formação de Professores e Práticas Interdisciplinares (PPGFPPI). ORCID: <http://orcid.org/0000-0002-2935-3403>. E-mail: paulo.schwingel@upe.br 
orientado hacia la realización de medidas preventivas y para la rehabilitación propiamente dicha.

PALABRAS CLAVE: Deporte. Fisioterapia. Primeros auxilios.

ABSTRACT: First aid is the care provided to victims of any accident or sudden injury before the arrival of the doctor, ambulance or any qualified health professional. The objective of this study is to identify the physiotherapist's way of acting in first aid in sport. This is a bibliographic review, in which 2 books and 8 scientific articles obtained in the databases LILACS, MEDLINE and SciELO were used from January to March 2018. The results showed that the physiotherapist will act in the sports first aid by means of the PRICE method. However, it is necessary to carry out new studies that emphasize this topic, so that we can have a greater theoretical contribution. The majority of the analyzed studies reported the role of physiotherapy more oriented to preventive measures and rehabilitation.

KEYWORDS: Sport. Physical Therapy. First Aid.

\section{Introdução}

Os primeiros socorros são os atendimentos prestados às vitimas de qualquer acidente ou mal súbito antes da chegada do médico, da ambulância ou de qualquer profissional qualificado da área de saúde (PASTERNAK, 2006). O objetivo desse socorro urgente é manter a vida e isentar o agravamento de lesões existentes até a chegada de ambulância ou durante o transporte até a instituição hospitalar (OLIVEIRA, 2002).

E a atividade esportiva é definida como todo movimento corporal produzido pelos músculos esqueléticos que resulte em um gasto energético. Justamente durante a sua realização os atletas podem sofrer diversas lesões devido a uma série de distintos fatores (GARCIA et al., 2009).

Por conta disso nas atividades esportivas faz-se necessária uma equipe de cuidados médicos imediatos e, dentre esses profissionais, o fisioterapeuta esportivo tem papel importante, sendo de fundamental importância na identificação do problema e atuando nos primeiros socorros prestados aos atletas lesionados.

Esse profissional tem a função de estar alerta às lesões e doenças e também deve atuar como responsável na prestação de cuidados e avaliação dos primeiros socorros. Analisando frequências absolutas, dentre as modalidades esportivas praticadas no Brasil, tais como natação, tênis, vôlei, Mixed Martial Arts (MMA) e basquete, nenhuma delas acarreta mais lesões que o futebol. Verifica-se nesta modalidade que as lesões mais comuns são contusões, entorses, estiramentos, distensões, fraturas e lesões de joelho (SANTACRUZ, 2012). 
Diante do exposto, o objetivo do presente estudo é identificar a forma de atuação do fisioterapeuta nos primeiros socorros no esporte.

\section{Metodologia}

Trata-se de uma revisão de literatura, do tipo descritiva, com abordagem qualitativa, sendo aquela que se realiza a partir do registro disponível, decorrente de pesquisas anteriores, em documentos impressos, como livros, artigos, teses, entre outros materiais bibliográficos disponíveis.

Utiliza-se de dados e/ou de categorias teóricas, já trabalhadas por outros pesquisadores, devidamente registrados, os textos tornam-se fontes dos temas a serem pesquisados e o pesquisador trabalha a partir das contribuições dos autores dos estudos analíticos constantes dos textos (SEVERINO, 2008).

Por intermédio do processo de pesquisa foram encontrados ao todo 696 artigos nas bases de dados utilizadas, os quais foram selecionados e catalogados, possibilitando a formação de uma biblioteca de artigos científicos onde todas as informações referentes aos artigos pudessem ser visualizadas.

Para efetivação da pesquisa, foi realizado um primeiro filtro, que envolve eliminar artigos duplicados e que não possuíam informações completas quanto a título, autores, periódicos e palavras-chave e que, por isso, impossibilitariam a análise. Nesse primeiro filtro foram eliminados 230 artigos, restando 466. Posteriormente, foi feita uma segunda filtragem de artigos, através da leitura do título do artigo e de uma avaliação em relação ao alinhamento, aos objetivos e à contribuição para a pesquisa. Nesse caso, ter os artigos dentro de um sistema de catalogação é providencial para auxiliar na produtividade do trabalho do pesquisador. Logo em seguida um novo filtro, por meio de uma leitura mais minuciosa, retirando assim 456 artigos, restando 08 artigos e 02 livros na base de dados.

Neste trabalho foram utilizados 2 (dois) livros e 8 (oito) artigos obtidos nas principais bases de dados disponíveis e irrestritos, sendo a Literatura Latino-Americana em Ciências da Saúde (LILACS), a Literatura Internacional em Ciências da Saúde (MEDLINE) e a Scientific Electronic Library Online (SciELO).

Foram utilizados como critérios de inclusão a utilização de artigos publicados em língua portuguesa, que abrangessem a fisioterapia desportiva e os primeiros socorros, independente do ano de publicação. Foram excluídos os trabalhos que não apresentassem os dados referentes ao 
objetivo e publicados em outros idiomas. As pesquisas foram realizadas no período compreendido entre janeiro e março de 2018.

\section{Resultados e Discussões}

A partir dos estudos analisados pode-se observar que a fisioterapia desportiva de acordo com Negrão (2002) é um componente da medicina esportiva e suas práticas e métodos são aplicados nas lesões com o propósito de recuperar, sanar e prevenir. Segundo Nascimento e Takanashi (2012) essa é uma das áreas de atuação da fisioterapia mais promissoras atualmente.

Conforme Silva, Brito e Sandoval (2009) a presença do fisioterapeuta em uma equipe de socorristas é extremamente relevante, pois este é um profissional especialista em biomecânica, sendo apto a prestar atendimento adequado na remoção da vítima sem agravar as lesões. Como também apresenta outros conhecimentos que o capacitam para atuar nos atendimentos de urgência e emergência.

Porém, quando se associa a primeiros socorros no esporte verifica-se uma carência de estudos que abrangem essa área. Por outro lado, a partir dos conhecimentos da área desportiva o fisioterapeuta vai apresentar um papel fundamental segundo a literatura. Nascimento e Takanashi (2012) reportam que no futebol inglês o médico atende presencialmente apenas uma vez por semana no clube esportivo, ficando a cargo do fisioterapeuta os primeiros atendimentos das lesões e de outras doenças.

Diante das modalidades desportivas mais realizadas no Brasil, o futebol aparece como sendo a que apresenta a maior frequência absoluta de lesões. Conforme Almeida et al. (2013) as lesões de maior incidência nesta modalidade são as contusões e as contraturas $(26,1 \%)$, seguidas de tendinites (13\%), distensões musculares, entorses, luxações $(8,7 \%)$, estiramentos e pubalgia $(4,3 \%)$.

Contusão é compreendida como a lesão que resulta de um golpe ou choque violento, com traumatismo compressivo de tecidos (DIAS; SCHNEIDER, 2014). Podendo ser leve ou grave, atingindo a musculatura, os vasos, nervos e estruturas adjacentes. Assim o fisioterapeuta, de imediato, atua de maneira a minimizar o dano tecidual local fazendo a aplicação do método denominado de PRICE, que é derivado do inglês: PROTECTION, REST, ICE, COMPRESSION e ELEVATION (na mesma ordem em português significa Proteção, Repouso, Gelo, Compressão e Elevação).

Em conformidade com Fernandes (2011) todos os componentes do PRICE irão trabalhar para reduzir as chances de novas lesões e minimizar o inchaço local, o que ajudará na prevenção 
de danos maiores e irá proporcionar uma reabilitação mais acelerada e/ou efetiva. O mesmo autor também relata o processo fisiológico inerente a esse procedimento, explicando quando o membro lesionado é colocado em repouso de imediato, previne-se uma retração muscular tardia por meio da redução do tamanho do hematoma.

Além disso, com o uso precoce da crioterapia haverá diminuição do hematoma, menor inflamação e uma regeneração acelerada e associada à compressão do membro. Este procedimento, que tem duração recomendada entre 15 e 20 minutos, diminui o fluxo da irrigação sanguínea no local. E, assim, com a realização do procedimento de elevação do membro é obtida diminuição da pressão hidrostática, fato que acarreta na redução do acúmulo de líquido no espaço intersticial.

\section{Considerações finais}

Os trabalhos analisados na presente revisão permitem concluir que o fisioterapeuta é um componente de fundamental importância na equipe de cuidados médicos para o atleta, uma vez que o método PRICE utilizado por ele no atendimento imediato das lesões tem elevada importância na prevenção de agravamento no quadro do esportista e acelera o processo de reabilitação do atleta, para que o mesmo tenha um retorno gradual e seguro ao esporte.

Porém, torna-se necessária a realização de novos estudos que enfatizem esse tema para que possamos aumentar o arcabouço teórico e assim obtermos dados mais precisos. A maioria dos estudos pesquisados relata o papel da fisioterapia voltado mais para a realização de medidas preventivas e também para a reabilitação propriamente dita.

\section{REFERÊNCIAS}

ALMEIDA, P. S. M.; SCOTTA, A. P.; PIMENTEL, B. de M.; BATISTA JUNIOR, S.; SAMPAIO, Y. R. Incidência de lesão musculoesquelética em jogadores de futebol. Rev. Bras. Med. Esporte. v. 19, n. 2, Mar/abr, 2013.

DIAS, P. F. F.; SCHNEIDER, C. Apostila II de fisiopatologia. Escola de Massoterapia SOGAB, 2014. Disponível em: www.sogab.com.br/apostilafisiopatologia2.pdf. Acessado em: 26 jan. 2019.

FERNADES, T. L.; PEDRINELLI, A.; HERNANDEZ, A. J. Lesão muscular - fisiopatologia, diagnóstico, tratamento e apresentação clínica. Rev. bras. ortop., São Paulo, v. 46, n. 3, 2011. 
GARCIA, J. L.; DALANO, C. L.; BORRAGINE, S. de O. F.; BRITO, C. A. F. Atividade física intencional e sua influencia na qualidade de vida: desafios para o profissional de Educação Física. Efdesportes, v. 14, n. 137, out., 2009.

NASCIMENTO, H. B.; TAKANASHI, S. Y. L. Lesões mais incidentes no futebol e a atuação da fisioterapia. Goiás, 2012. Disponível em:

http://www.fisioterapia.com/public/files/artigo/artigo06_2.pdf. Acessado em: 10 fev. 2019.

NEGRÃO, S. S. Introdução à fisioterapia desportiva. 2002. Disponível em:

http://www.personalfit.com.br/artigos.asp?artigo=246. Acesso em: 25 fev. 2019.

OLIVEIRA, B. M. Trauma - atendimento pré-hospitalar. São Paulo (SP): Atheneu, 2002.

PASTERNAK, J. Manual de primeiros socorros. São Paulo, SP: Ática, 2006.

SANTACRUZ, A. Conheça as lesões mais comuns em cada modalidade esportiva. 2012. Disponível em: http://zh.clicrbs.com.br/rs/vida-e-estilo/vida/noticia/2012/06/conheca-aslesoes-mais-comuns-em-cada-modalidade-esportiva-3806182.html. Acessado em: 16 fev. 2019.

SEVERINO, A. J. Metodologia do trabalho científico. 23. ed. São Paulo: Cortez, 122 p., 2008.

SEVERINO, A. J. Pesquisa educacional: da consistência epistemológica ao compromisso ético. Revista Ibero-Americana de Estudos em Educação, [S.1.], p. 900-916, jun. 2019. ISSN 1982-5587. Disponível em:

https://periodicos.fclar.unesp.br/iberoamericana/article/view/12445. Acesso em: 12 july 2019. doi: https://doi.org/10.21723/riaee.v14i3.12445.

SILVA, D. P.; BRITO, R. C.; SANDOVAL, R. A. Inserção do fisioterapeuta em uma equipe de primeiros socorros. Efdesportes.com. v. 13, n. 129, fev. 2009. Disponível em:

http://www.efdeportes.com/efd129/insercao-do-fisioterapeuta-em-uma-equipe-de-primeirossocorros.htm. Acessado em: 12 fev. 2019.

\section{Como citar este artigo:}

PONTE DA SILVA, Suelena; LOPES SOARES, Stela; SCHWINGEL, Paulo Adriano. Formas de atuação do fisioterapeuta em primeiros socorros nas modalidades desportivas: uma revisão da literatura brasileira. Temas em Educação e Saúde, Araraquara, v. 15, n. 1, p. 18-23, jan./jul., 2019. ISSN 2526-3471. DOI: 10.26673/tes.v15i1.12271.

Submetido em: 17/02/2019.

Aprovado em: 04/04/2019 